\title{
Sutureless aortic valves: A game changer, or niche tool in an expanding toolbox?
}

\author{
Davis C. Drinkwater, MD, MSc
}

From the TriStar Cardiovascular Surgery, Centennial Medical Center, Nashville, Tenn.

Disclosures: Author has nothing to disclose with regard to commercial support.

Received for publication Sept 21, 2016; accepted for publication Sept 22, 2016; available ahead of print Nov 4, 2016.

Address for reprints: Davis C. Drinkwater, MD, MSc, TriStar Cardiovascular Surgery, Centennial Medical Center,

2400 Patterson St, Suite 307, Nashville, TN 37203 (E-mail: davis.drinkwater@hcahealthcare.com).

J Thorac Cardiovasc Surg 2017;153:252-4

$0022-5223 / \$ 36.00$

Copyright (c) 2016 by The American Association for Thoracic Surgery

http://dx.doi.org/10.1016/j.jtcvs.2016.09.061

The field of aortic valve replacement, particularly for stenosis, has grown rapidly during the past decade. The INTUITY valve (Edwards Lifesciences Corp, Irvine, Calif) from the TRANSFORM US clinical trial is presented by Barnhart and colleagues ${ }^{1}$ in the current issue of the Journal as one of a small group of rapid-deployment sutureless valves. This report joins other recent clinical reports of this updated technology, which was first described more than 50 years ago. ${ }^{2}$ It represents a single-arm trial for safety and efficacy totaling 839 patients in 29 institutions during a 3-year period. The modification of the standard and wellstudied Magna Ease PERIMOUNT Valve (Edwards Lifesciences) with transcatheter aortic valve replacement (TAVR; Sapien; Edwards Lifesciences) technology enables sutureless rapid-deployment aortic valve replacement (RDAVR). This is attractive because of concern for longterm valve integrity in any recently introduced biologic valve in both RDAVR and TAVR procedures. ${ }^{3}$ Barnhart and colleagues ${ }^{1}$ report shorter cardiopulmonary bypass and aortic crossclamp times, 20 to 30 minutes on average. These are comparable to the European experience with this and other RDAVR valves, which has ranged from 13 to 28 minutes. ${ }^{4,5}$ Because there were no trial controls, Barnhart and colleagues ${ }^{1}$ used as a comparison contemporary Society of Thoracic Surgeons data for standard aortic valve replacement surgery (SAVR), which may have potentially inflated the actual time saved because these data more broadly represent low- as well as high-volume valve surgery centers and include "all comers," as opposed to the uniformly high-volume programs and selective patient population within the TRANSFORM Trial. The exclusions are understandable in the context of an early-phase clinical trial and included primary aortic regurgitation, emergency surgery, previous aortic valve surgery, presence of root aneurysm or endocarditis in the previous 3 months, and intraoperative heavy annular or anterior mitral leaflet calcification.

Collectively, we may accept the conclusion of Barnhart and colleagues ${ }^{1}$ on the basis of this and other reports that the use of the RDAVR technology will result in some

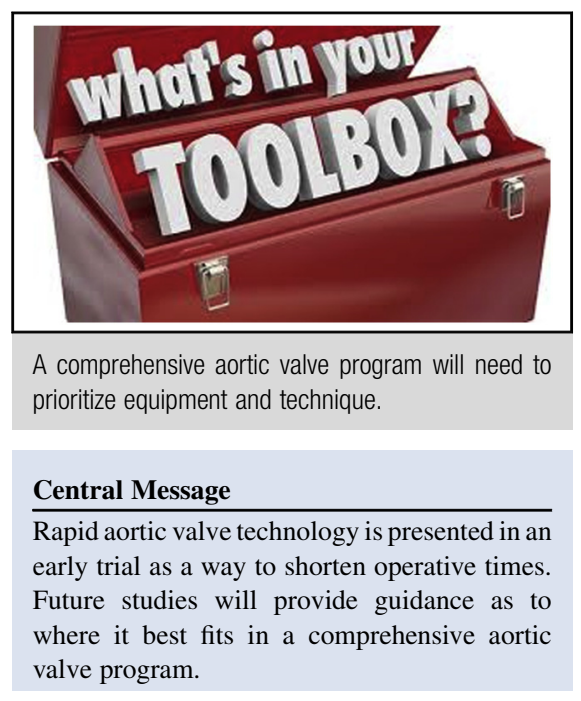

See Article page 241 .

conservation of operative time. It should also be recognized, however, that an overall quality improvement goal to shorten surgical procedure times has influenced all aspects of cardiac surgery as well. Among these efforts, recently introduced automated suture fixation as well as singleshot cardioplegia represent two examples have arguably reduced SAVR procedure times.

Individually, we must evaluate the amount of time needed to carry out RDAVR, which is to remove and débride the aortic valve and annulus in the standard manner, place 3 fixation sutures, and accurately size and deploy the RDAVR. This should be compared with say an additional 12 sutures in SAVR technique, while weighing any potential time benefit against the 1-year TRANSFORM follow-up data, which show a significant number of patients $(14 \%)$ receiving pacemakers, as well as the presence of perivalvular leak (PVL) of $2+$ or greater in $9 \%$ of patients available for echocardiographic studies. There have been concerning reports of diminished survivals among patients undergoing TAVR with any significant PVL of $2+$ or greater, and the fact that the majority of these patients $(6.9 \%)$ were in the $2+$ or mild category should still raise some concerns, despite the study's definition not including the majority of PVL as significant. Nine patients were considered to have significant PVL and underwent reoperation for severe PVL in this trial -2 early and 7 during the course of 2 years of follow-up. This leaves, however, a large number of patients with PVL who face potentially adverse long-term 
outcomes. A design whereby the cloth skirt for inflation and contact fixation is located below the valve prosthesis may play a role both in the reported relatively high rate of PVL, despite excision of leaflets and calcium similar to SAVR, and in the increased pacemaker rates by placing the greatest circumferential pressure in the left ventricular outflow tract near the membranous septum and conduction. In fairness to the INTUITY data, both RDAVR prostheses currently in use are troubled by the issue of pacemaker need at least 2 to 3 times the level seen with SAVR. ${ }^{6}$ There has been a second-generation INTUITY valve (8300 AB), and no doubt there will be further modifications in both technique and design in an attempt to minimize and avoid these complications. Barnhart and colleagues ${ }^{1}$ noted that a conversion rate of $5.5 \%$ to the use of a standard valve was due in large part to an early learning curve and the lack of a "roll in," which may also be reflected in the early outcomes. Barnhart and colleagues ${ }^{1}$ point out that the majority of patients who received pacemakers had preexisting conduction defects. This risk factor also applies to SAVR, however, where it has not been the same issue-a recent comparison of the standard Magna Ease (SAVR) valve and the INTUITY (RDAVR) valve reported $2 \%$ and $9 \%$ pacemaker implantation rates, respectively. ${ }^{7}$ Preexisting conduction disturbances will also influence TAVR valve selection and now might be a consideration for choosing SAVR instead of RDAVR in selected cases.

The TRANSFORM US Clinical Trial joins other trials introducing us to the potential benefits of RDAVR relative to SAVR technology. The SAVR results are the standard for the RDAVR comparison because the sutureless valve is largely competing with SAVR procedures. This trial listed $40 \%$ as requiring a minimal incision, including the majority performed through a ministernotomy or a hemisternotomy and only $8 \%$ through an anterior thoracotomy. Most patients undergoing SAVR can benefit and increasingly are benefiting from a minimal incision direct approach, particularly the partial sternotomy. Other than potential and somewhat variable time saving, the RDAVR may be useful in reoperations on aortic homografts, stentless valves, or porcelain aortas and calcified aortic roots, either as part of a planned approach or when encountered intraoperatively. Of course TAVR, if available, is frequently considered prospectively in these higher risk situations when there is no overriding concomitant need for an open approach. If there is an indication for RDAVR, for surgeons who admire the long bloodline of this PERIMOUNT series, the INTUITY valve would be a consideration.

Another issue that is "real world" and greatly effects the programmatic introduction of less invasive technology for aortic valve replacement is the direct cost. One should estimate a potential 2-fold increase relative to the standard valve costs according to research and development and development expense. A projection of shorter operating room times, resulting in projected less transfusion and shorter ventilation and intensive care unit times, may not become a reality when fairly modest operative time saving is considered. In contrast, TAVR is an example of increased direct costs that do translate directly to decreased perioperative costs by making it routinely possible to discharge high-risk patients from the hospital in 1 to 2 days after a less-invasive procedure done under sedation. For SAVR, the effectiveness of improved cardioplegia protection and modern conduct of cardiopulmonary bypass and the more standardized perioperative management combine to make this a less-definite prognosis and continue to improve SAVR results to an overall operative mortality of $2.1 \%$ (Society of Thoracic Surgeons database 2015). When one considers the role of sutureless valves in an aortic valve program, the RDAVR valve may be a niche tool that is useful for selected cases of longer and more complicated surgery involving a number of bypass vessels or additional valve repair or replacement. Most experienced surgeons may find the current cost and trade-offs too divergent from SAVR results for frequent use in those circumstances.

In the case of isolated aortic valve replacement, it is unlikely that RDAVR will displace TAVR in the "minimal" approach sphere, because indications for the latter are relaxing to include patients at lower risk. TAVR has advantages of peripheral access in most cases and of the best hemodynamics (less gradient and patient-prosthesis mismatch) as measured against both RDAVR and SAVR. ${ }^{8,9} \mathrm{PVL}$ is a continued but decreasing issue with both design, as well as with technique modifications in the TAVR valves. The one overarching question as younger and healthier patients are considered is that of valve longevity and freedom from structural valve deterioration. Some recent reports are favorable at 5 years for a low incidence of structural valve deterioration in current TAVR valves, ${ }^{10,11}$ but clearly longer follow-up, particularly that of the younger patients, will be informing the medical community's decisions. The capability of "rescue" valve-in-valve placement for future structural valve deterioration will no doubt be factored into discussions by patients and physicians regarding valve selection. Because of a combination of factors, including lifestyle goals and interconnectivity through widespread internet information, it is a given that patients will play an increasingly independent role in the selection of their aortic valve prostheses. No amount of "minimal" incisions will trump a potential peripheral access under sedation for most determined patients. For more complex surgeries, RDAVR with prostheses such as the INTUITY valve may become a niche tool if the outcomes can achieve parity with those of SAVR.

\footnotetext{
References

1. Barnhart GR, Accola K, Grossi EA, Woo J, Mumtaz MA, Sabik JF, et al; TRANSFORM Trial Investigators. TRANSFORM (Multicenter Experience
} 
With Rapid Deployment Edwards INTUITY Valve System for Aortic Valve Replacement) US clinical trial: performance of a rapid deployment aortic valve. J Thorac Cardiovasc Surg. 2017;153:241-51.e2.

2. Magovern GJ, Kent EM, Cromie HW. Sutureless artificial heart valves. Circulation. 1963;27:2784-8.

3. Johnston DR, Soltesz EG, Vakil N, Rajeswaran J, Roselli EE, Sabik JF III, et al. Long-term durability of bioprosthetic aortic valves: implications from 12,569 implants. Ann Thorac Surg. 2015;99:1239-47.

4. Muneretto C, Alfieri O, Cesana BM, Bisleri G, De Bonis M, Di Bartolomeo R, et al. A comparison of conventional surgery, transcatheter aortic valve replacement, and sutureless valves in "real-world" patients with aortic stenosis and intermediate-to high-risk profile. J Thorac Cardiovasc Surg. 2015;150:1570-9; discussion 1577-9.

5. Borger MA, Moustafine V, Conradi L, Knosalla C, Richter M, Merk DR, et al. A randomized multicenter trial of minimally invasive rapid deployment versus conventional full sternotomy aortic valve replacement. Ann Thorac Surg. 2015;99:17-25.

6. Fischlein T, Meuris B, Hakim-Meibodi K, Misfeld M, Carrel T, Zembala M, et al; CAVALIER Trial Investigators. The sutureless aortic valve at 1 year: a large multicenter cohort study. J Thorac Cardiovasc Surg. 2016;151:1617-26.e4.
7. Andreas M, Wallner S, Habertheuer A, Rath C, Schauperl M, Binder T, et al. Conventional versus rapid-deployment aortic valve replacement: a singlecentre comparison between the Edwards Magna valve and its rapiddeployment successor. Interact Cardiovasc Thorac Surg. 2016;22:799-805.

8. D’Onofrio A, Salizzoni S, Rubino AS, Besola L, Filippini C, Alfieri O, et al. The rise of new technologies for aortic valve stenosis: a comparison of sutureless and transcatheter aortic valve implantation. J Thorac Cardiovasc Surg. 2016;152: 99-109.e2.

9. Zorn GL III, Little SH, Tadros P, Deeb GM, Gleason TG, Heiser J, et al. Prosthesis-patient mismatch in high-risk patients with severe aortic stenosis: a randomized trial of a self-expanding prosthesis. J Thorac Cardiovasc Surg. 2016;151:1014-22. 1023.e1-3.

10. Papadopoulos N, Wenzel R, Thudt M, Doss M, Wimmer-Greinecker G, Seeger F, et al. A decade of transapical aortic valve implantation. Ann Thorac Surg. 2016; 102:759-65.

11. Mack MJ, Leon MB, Smith CR, Miller DC, Moses JW, Tuzcu EM, et al. 5-year outcomes of transcatheter aortic valve replacement or surgical aortic valve replacement for high surgical risk patients with aortic stenosis (PARTNER 1): a randomised controlled trial. Lancet. 2015;385:2477-84. 